\title{
The contribution of an intervention program for improving quality of life of older adults
} Rona Bar-Netzer, Bocoș Mușata 


\title{
The contribution of an intervention program for improving quality of life of older adults
}

\author{
Rona Bar-Netzer ${ }^{a *}$, Muşata Bocoş ${ }^{b}$ \\ a Doctoral School "Educational, Reflection, Development", Babeş-Bolyai University, 7 Sindicatelor Street, 400029, Cluj-Napoca, Romania \\ ${ }^{b}$ Faculty of Psychology and Educational Sciences, Babeş-Bolyai University, 7 Sindicatelor Street, 400015, Cluj-Napoca, Romania
}

*Corresponding author: ronab743@gmail.com

\section{Abstract}

\section{Keywords:}

FORCE program, Quality of life, , older adults, psychoeducation
This paper discusses the contribution of a new intervention program for older adults (FORCE), developed by the author (Schwartzman Bar-Netzer, 2016). The FORCE Program represents an innovative approach to health promotion with older adults integrating psycho-education and exercising core muscles, for improving everyday quality of life (QOL). The research conceptual framework is based on The Whole Person Wellness Model (Kang \& Russ, 2009) and the TransTheoretical Model -Stages of Change (Prochaska, et. al., 2008).

95 women and 11 men aged 60-90 participated in the program for 12 months. Two experimental groups- one of core muscle workout $(\mathrm{CM}: \mathrm{n}=28)$ and one with home equipment $(\mathrm{CMI}: \mathrm{n}=59)$, and a control group $(\mathrm{CoG}: \mathrm{n}=19)$ participated in the research.

The research tool was the SF-36 Health Survey Quality of Life Questionnaire (Bentor \& Epshtein, 2001) before and after the intervention program. Eight parameters of QOL were examined: Physical functioning, Limited physical health, Limited emotional health, Energy, Emotional wellbeing, Social functioning, General health, Pain.

The results show significant improvement, following the program, on 7 of the 8 parameters related to QOL in the 2 experimental groups compared to the control group. These findings were further supported in the research when participants reported undergoing significant improvement in their quality of life and their capabilities in everyday activities.

The research conclusions hold the potential for developing new methods to substantially improve the quality of life and wellbeing of this growing population on whom there is limited empirical research.

\section{Zusammenfasung}

\section{Schlüsselworte:}

FORCE- Programm,

Lebensqualität,

ältere Menschen,

Psychoedukation
In diesem Bericht wird der Beitrag eines neuen Interventionsprogramms für ältere Menschen (FORCE) erörtert, das vom Autor Schwartzmann Bar-Netzer (2016) entwickelt wurde. Das FORCE-Programm stellt einen innovativen Ansatz zur Gesundheitsförderung dar, bei dem ältere Menschen die Psychoedukation integrieren und die Rumpfmuskulatur trainieren, um die tägliche Lebensqualität (QOL) zu verbessern. Der konzeptionelle Rahmen für die Forschung basiert auf dem Whole Person Wellness-Modell (Kang und Russ, 2009) und den transtheoretischen Modellstadien des Wandels (Prochaska, et al., 2008). 95 Frauen und 11 Männer im Alter von 60-90 Jahren haben 12 Monate lang an dem Programm teilgenommen. Zwei experimentelle Gruppen - eine der Kernmuskeltrainingseinheiten (CM: $\mathrm{n}=28)$ und eine mit Heimausrüstung (CMI: $\mathrm{n}=59)$ sowie eine Kontrollgruppe (CoG: $\mathrm{n}=19)$ nahmen an der Forschung teil. Das Forschungsinstrument war der Fragebogen zur Lebensqualität des SF-36 (Bentor und Epshtein, 2001) vor und nach dem Interventionsprogramm. Acht Parameter der Lebensqualität wurden untersucht: Körperliche Funktionsfähigkeit, begrenzte körperliche Gesundheit, eingeschränkte emotionale Gesundheit, Energie, emotionales Wohlbefinden, soziales Funktionieren, allgemeine Gesundheit und Schmerz. Die Ergebnisse zeigen eine signifikante Verbesserung nach dem Programm bei 7 der 8 Parameter in Bezug auf die Lebensqualität in den 2 Versuchsgruppen im Vergleich zur Kontrollgruppe. Diese Ergebnisse wurden in der Studie weiter untermauert, als die Teilnehmer in eingehenden Interviews über signifikante Verbesserungen ihrer Lebensqualität und Alltagstauglichkeit berichteten. Die Forschungsergebnisse beinhalten das Potenzial für die Entwicklung neuer Methoden zur erheblichen Verbesserung der Lebensqualität und des Wohlbefindens dieser wachsenden Bevölkerung, für die es nur begrenzt empirische Forschung gibt.

\section{Introduction}

Studies prove that during the third and fourth age quality of life suffers significant decline due both to evolutionary causes and development of modernization. There is a rising need, along with increased life expectancy, for intervention programs that assist this population in improving its quality of life from educational, physical, emotional and social aspects. The gap in knowledge is that there is a lack of studies focused on this age group and not enough intervention programs developed in Israel and elsewhere. The current study developed a designated intervention 
program (FORCE) for the third and fourth ages, which aims to improve the quality of life and sense of efficacy of these age groups. The FORCE program is a group activity relating to psycho-educational aspects and physical activity that strengthens core muscles, emphasizing emotional and social aspects of quality of life (QOL) in addition to physical aspects.

This article relates to the first and second parts of the research that deal with development of the program and assessing its contribution to the participants' quality of life compared to the control group that took part in a conventional physical training program for the elderly.

\section{Theoretical foundations}

The research conceptual framework of the FORCE workout intervention program was based on two theoretical models of behavioral and educational modification: The Whole Person Wellness Model (Kang \& Russ, 2009) and The Trans-Theoretical Model (TTM) -Stages of Change (Prochaska, et. al., 2008).

\section{A. The Whole Person Wellness Model (Kang \& Russ, 2009)}

This model describes behavioral change that contains a holistic approach with six dimensions of wellness. In the FORCE workout program, the idea was to attain five of the wellness aspects: social (group interaction), intellectual (verbally explaining), spiritual (mind and body), emotional (group coping) and physical (core muscle workout). Each of these aspects adds to an individual's wellness, operating in unison to generate behavioral changes.

\section{B. The Trans-Theoretical Model (TTM) -Stages of} Change (Prochaska, et. al., 2008). This model conceptualizes the intentional behavioral change process using a bio-psycho-social model. It relies on 6 stages of change: pre-contemplation, contemplation, preparation, action and maintenance. There is a strong connection between stage construct and time.

\subsection{The FORCE new Intervention Program}

The FORCE program was designed by the researcher, to educate for better overall QOL for the elderly people aged 60 or more. With 20 years' teaching experience in this field and while training seniors using a unique method, the author noticed physical and mental changes in their perception of training and in feedback received from the participants. The FORCE program provides twice-weekly activities for older adults in an appropriate studio in groups of 8 to twenty elderly persons in 11 settlements in Israel. The methods in the FORCE program promote flexibility of the body and the brain and facilitate sensory motor skills and cognitive and physical control. The classes are a combination of psycho-education based on methodological explanations and practical workout (Kok \& Reynolds, 2017). Developing interpersonal communication, which enhances social connections, had been found in the literature (Charles \& Carstense, 2010) to be a significant factor for quality of life at this age. The program helps the participants develop self-motivation: success and improvement in daily quality of life leads to the desire to attend the FORCE program regularly.

The different interventional tools are based on encouraging participants to increase daily activities knowing they are working their core muscles, destabilizing the support base and diminishing intra-spinal load in sitting, lying or leaning.

\section{Problem Statement-Gap in knowledge}

The role of the teaching staff is to help the elderly overcome barriers and intelligently integrate physical activity into their daily life (Dunsky, et al., 2015). Studies that investigated the influence of physical activity on mental function found both aerobic activity and resistance training to be effective (Dunsky et al., 2013). A reverse connection was found between physical activity and loneliness (Netz et al., 2012b) and decreased mortality among physically active people (Dunsky, et al., 2015). These studies prove the importance of developing a special program for promoting QOL in this age. Most studies that deal with older adults examine the influence of dynamic programs that include aerobic activities and classes, jogging and cycling on quality of life. Since the number of studies on Core Muscles programs for the elderly, combining educational, social and physical dimensions is relatively small, the current study examines the effect of FORCE program on improving QOL among older adults.

\section{Methodology}

\section{The aims of the Study}

- To develop an intervention program (FORCE) based on psycho-education and strengthening core muscle training for improving quality of life of third and fourth age elderly people. 
- To examine the contribution of the FORCE intervention program to quality of life of older adults.

\subsection{Research Population}

106 participants aged 60-90, took part in the study voluntarily. They were recruited from among 11 communities in a Regional Council, groups that undergo relatively regular training and were divided into three random groups: Two experimental groups: one of core muscle workout (CM: $\mathrm{n}=28)$ and one of core muscle workout with home equipment (CMI: $n=59)$, and a control group who do not participate in the FORCE program (CoG: $\mathrm{n}=19$ ). This is a multicultural population that includes orthodox, holocaust survivors and secular people coming from a variety of socio-economic statuses that influence their wellbeing and lifestyle.

\subsection{Research tool}

During their first assessment session, participants completed a demographic questionnaire - the Instrumental Activities Daily Living (IADL) questionnaire (Lawton, 1969; Dunsky, et al, 2017). Quality of life (QOL) was examined using the SF-36 Health Survey Quality of Life Questionnaire (Bentor \& Epshtein, 2001), that were given to the participants at the beginning and end of the study (after 12 months). Eight parameters of QOL were examined: Physical functioning, Limited physical health, Limited emotional health, Energy, Emotional wellbeing, Social functioning, General health, Pain.

\section{Results}

Table 1 provides a comparison between the experimental and control groups, relating to eight parameters of QOL in the questionnaires.

Table no. 1. Comparing the three study groups (CoG, CM\&CMI) in eight parameters of QOL (means \pm S.D) $*$ Time main effect $(p<0.05) ;{ }^{\wedge}$ Group main effect $p \leq 0.05$; \# Interaction $p<0.05$

\begin{tabular}{|c|c|c|c|c|c|c|c|c|c|c|c|c|}
\hline \multirow{3}{*}{$\begin{array}{l}\text { Groups } \\
\text { Time } \\
\text { Measure }\end{array}$} & \multicolumn{4}{|c|}{$C M I(N=59)$} & \multicolumn{4}{|c|}{$C M(N=28)$} & \multicolumn{4}{|c|}{$\operatorname{CoG}(N=9)$} \\
\hline & \multicolumn{2}{|c|}{ PRE } & \multicolumn{2}{|c|}{ POST } & \multicolumn{2}{|c|}{ PRE } & \multicolumn{2}{|c|}{ POST } & \multicolumn{2}{|c|}{ PRE } & \multicolumn{2}{|c|}{ POST } \\
\hline & $M$ & $S D$ & $M$ & $S D$ & $M$ & $S D$ & $M$ & $S D$ & $M$ & $S D$ & $M$ & $S D$ \\
\hline Physical functioning* & 60.24 & 32.37 & 70.75 & 27.46 & 68.52 & 27.64 & 81.48 & 18.84 & 66.66 & 28.05 & 65.43 & 27.04 \\
\hline Limited Physical health & 56.73 & 41.56 & 61.54 & 31.11 & 47.22 & 38.41 & 61.81 & 31.01 & 69.44 & 39.09 & 60.41 & 36.04 \\
\hline $\begin{array}{c}\text { Limited Emotional } \\
\text { Health^}\end{array}$ & 71.79 & 41.83 & 82.05 & 32.97 & 44.44 & 44.10 & 74.07 & 36.43 & 81.48 & 33.79 & 81.48 & 33.79 \\
\hline Energy*;\# & 50.88 & 25.52 & 64.42 & 18.99 & 22.11 & 12.25 & 62.36 & 14.95 & 52.77 & 12.52 & 52.77 & 12.02 \\
\hline Emotional wellbeing*;^;\# & 59.16 & 26.90 & 74.46 & 14.00 & 17.82 & 11.01 & 50.99 & 16.92 & 62.22 & 9.82 & 51.44 & 13.40 \\
\hline Social Functioning* & 74.03 & 29.98 & 85.10 & 18.71 & 66.67 & 29.32 & 80.56 & 18.87 & 87.50 & 12.50 & 83.33 & 12.50 \\
\hline General health* & 61.60 & 24.85 & 72.79 & 16.34 & 53.47 & 31.73 & 70.65 & 17.31 & 69.72 & 21.87 & 65.50 & 20.66 \\
\hline Pain*;\# & 52.98 & 30.70 & 69.71 & 21.10 & 41.39 & 30.57 & 72.50 & 19.53 & 50.27 & 14.05 & 45.00 & 14.89 \\
\hline
\end{tabular}

Two-way ANOVA with repeated measurements (group X time) was carried out. As can be seen, the three groups were compared before and after the intervention.

Significant improvement was found on 6 parameters during the study: Physical functioning; Limited Emotional functioning; Energy; Emotional wellbeing; Social functioning; General health. In the Limited Physical health parameter there was an improvement but not significant.
As for the pain parameter - the experimental groups suffered greater pain than the control group. There was interaction $(\mathrm{p}=0.02)$ group $*$ time.

Figure no. 1 presents the results of the Pain parameter of the three study groups. 
Figure no. 1. The results of the Pain parameters of the three study groups (CMI, CM and CoG)

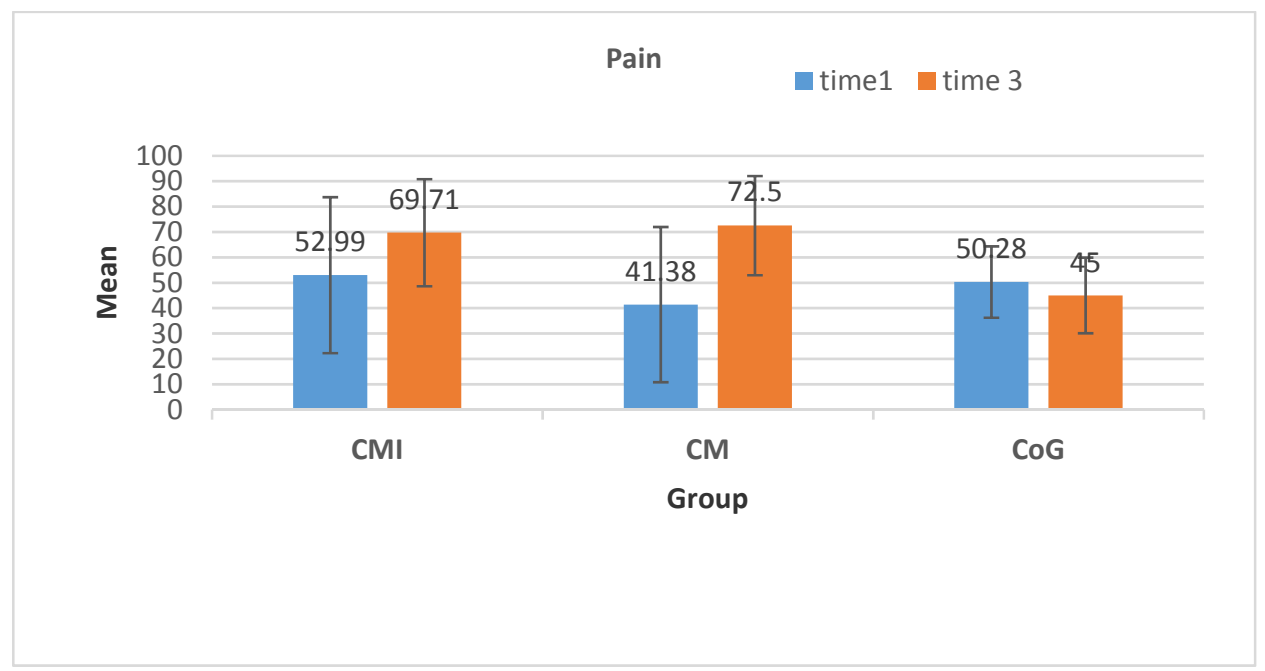

Another important finding shown in table no. 1 is that the experimental group that used home instruments (CMI) attained higher improvement in their quality of life compared to the experimental group (CM) that took part only in the FORCE program in bi-weekly training.

\section{Discussion}

Research findings show significant improvements of quality of life among third and fourth age persons who participated in the FORCE program. This section discusses the above findings in view of theories and previous research on this subject.

\subsection{Energy parameter of QOL (vitality)}

There is a biological-developmental component that influences decrease in motion, the gradual decline in physical activities with age (Dunsky, et al., 2015). This leads to decline in the motivation to move, not only that ability to move. Additionally, a reverse connection was found between physical activity and loneliness (Netz et al., 2012b) and less mortality among the physically active (Stessmen et al., 2009). Developing interpersonal communication in exercise circles helps develop social connections. Participants have the ability to change personal habits due to physical and emotional changes that occur with age and the ability to use these tools to deal with aging (Dunsky, et al., 2015). The research findings confirm that the FORCE program which combines psycho-education aspects with guided physical training leads to improvement in the Energy parameter among the experimental groups compared to the control group.

\subsection{Emotional Wellbeing}

Mental health and emotional wellbeing are as important in older age as at any other time of life.

The elderly has the ability to adapt to changes and have a positive outlook to the changes involved in ageing (Khan \& Tahir, 2014). The study findings show improvement in emotional wellbeing and quality of life in the two experimental groups, following participating in the FORCE program, compared to lack of advancement in the control group. The study findings support the literature maintaining that engagement in physical activity is very important to the elderly and effects their subjective wellbeing and depressive symptoms (Pudrovska \& Anishkin, 2013).

\subsection{Pain parameter (bodily pain)}

The research findings related to the Pain parameter showed the control group had lower pain level than the experimental groups, in the end of the program. During the classes, the experimental groups were given verbal explanations on anatomy, physiology, forms of training, so they were able to comprehend the way exercises were selected and applied. Acquaintance with their body and attention to minor changes that occur in it was both an advantage and a disadvantage. The disadvantage is in knowing how to focus their pain, as well as use solutions 
to suppress and remove pain. Among both experimental groups, in particular the CMI group, one may see excess comprehension, explaining the results of understanding pain interpretation, and that may explain why the experimental groups' results are higher. Furthermore, these groups began to move correctly and therefore the arthro-kinematic movements (deep muscle movements) are stronger raising capability but also increasing pain (McGill et al., 2014). Another possible explanation is that due to the interaction between the researcher and participants, they tended to expose their pain more than the control group. This research on the FORCE program, is one of the first research studies to test the efficacy of multiple compared to single behavior change interventions in older adults. The research findings provide important information not only on outcomes, but also on the process of behavioral change in older adults.6. Conclusions and contribution to knowledge

On the theoretical level, the FORCE program represents an innovative approach to health promotion with older adults. The program relies on a communitybased recruitment and partnership model, utilizing a public health approach to an entire population.

This research on the FORCE Program may extend and enhance our knowledge of quality of life promotion of this age.

On the practical level, this research holds the potential for developing new methods to substantially improve the health and wellbeing of this growing population, gain new and important insights into how older adults change their health-related behavior.

\section{The study Limits:}

The study sample is relatively small. However, this is derived mainly from the research population of third age from 11 communities who took part in a 12-month study. This is not easy considering their age.

\section{Future research directions}

A continued study is recommended to accompany the participants in their second year of the program in order to determine if the improvement found in this research continue to influence their quality of life. Further research in different social-economic surroundings is recommended, as well as a larger number of male and female participants, in order to comprehend the influence of the program on quality of life. The study findings and conclusions have universal implications since one may develop similar programs for the third and fourth age on a global level. This may significantly improve their quality of life, consciously and subconsciously influencing their cognitive, social and emotional wellbeing.

\section{Authors note:}

Rona Bar-Netzer is a coordinator and instructor of the the $3^{\text {rd }}$ age adults. She is Involved in an education project concerning the welfare of the elderly in Israel. She is a $\mathrm{PhD}$ student at UBB in Romania. Her research areas are aimed to develop and explore an intervention program (FORCE) that contributes to the quality of life and sense of efficacy of third and fourth age to improve everyday activity. She is teaching at Campus Ciim in T-A University.

Muşata Bocoş is a University Professor and Ph.D. Coordinator at the Faculty of Psychology and Sciences of Education (Babeș-Bolyai University, Cluj-Napoca, Romania). She has obtained a Ph.D. in Educational Sciences in 1997 at Babeș-Bolyai University. Her research interests are reflected in a series of studies and articles published in important national and international journals. Her teaching activity covers several domains such as the theory and methodology of curriculum, general didactics, and educational research.

\section{References}

Bentor, N. \& Epshtein, S. (2001). SF-36: A tool for measuring and evaluating quality of life related to health. Gerontology. Journal of Aging Issues, 28(3-4), 187-216 (In Hebrew).

Charles, S., \& Carstensen, L. L. (2010). Social and Emotional Aging. Annual Review of Psychology, 61: 383-409. Doi: 10.1146/annurev.psych.093008.100448.

Dunsky, A., Zeev, A., \& Netz, Y. (2017). Balance Performance Is Task Specific in Older Adults. Hindawi BioMed Research International. Article ID 6987017, 7 pages. Retrieved from https://doi.org/10.1155/2017/6987017.

Dunsky, A., Netz, Y. \& Argov, E. (2015). Physical Activity to Maintain Function in the Ascension Stage. In a D. Prilutzky, \& M. Cohen (Ed), Practical Gerontology A Professional Overview of Working with Older Adults, 
2(25) (pp: 417-444). Joint Israel Eshel Jerusalem (In Hebrew).

Dunsky, A., Zach, S., Zeev, A., Goldsmith, R., Shimony, T., Goldbourt, U. \& Netz, Y. (2013). Level of physical activity and anthropometric characteristics in old age results from a national health survey (Submitted for publication to IMAG). European Review of Aging and Physical Activity, 11(2), 149-157.

Khan, A.R. \& Tahir, I. (2014). Influence of Social Factors to the Quality of Life of the Elderly in Malaysia. Open Medicine Journal, 1, 29-35.

Kang, M., \& Russ, R. (2009). Activities that promote wellness for older adults in rural communities. Journal of Extension, 47, 1-5.

Kok, R.M., \& Reynolds, C.F. (2017). Management of Depression in Older Adults. JAMA, 317(20), 2114-2122. Doi:10.1001/jama.2017.5706.

Lawton, M.P \& Brody, E.M. (1969). Assessment of older people: self-maintaining and instrumental activities of daily living. The Gerontologist, 9(3), 179-186.

McGill, S.M., Cannon, J., \& Andersen, J.T. (2014). Analysis of pushing exercises: muscle activity and spine load while contrasting techniques on stable surfaces with a labile suspension strap training system. J Strength Cond Res, 28(1), 105-116. Doi:10.1519/JSC.013e3182a99459.

Netz, Y., Goldsmith, R., Shimony, T., Arnon, M. \& Zeev, A. (2012b). Loneliness is associated with an increased risk of sedentary life in older Israelis. Aging \& Mental Health. Doi:10.1080/13607863.2012.715140.

Prochaska, J.O., Butterworth, S., Redding, C.A., Burden, V., Perrin, N., Lea, Michael, Flaherty, Robb M., and Prochaska, J.M. (2008). Initial efficacy of MI, TTM tailoring, and HRI's in multiple behaviors for employee health promotion. Preventive Medicine, 46, 226-231.

Pudrovska, T., \& Anishkin, A. (2013). Early-life socioeconomic status and physical activity in later life: evidence from structural equation models. Journal of Aging and Health. 25(3), 383-404.

(Schwartzman) Bar-Netzer, R. (2016). Active Ageing and Effective Learning for Enhanced Quality of Life. The European Proceedings of Social \& Behavioural Sciences EpSBS, Volume XVIII, Pages 544-551. The European Proceedings of Social \& Behavioural Science EpSBS. Babeş-Bolyai University, Cluj-Napoca, Romania. 